\title{
Role of hysteroscopy and histopathology in evaluating patients with abnormal uterine bleeding
}

\section{Nighat Firdous ${ }^{1}$, Samar Mukhtar $^{2 *}$, Sheikh Bilal ${ }^{1}$, Salma Kounsar Beigh ${ }^{3}$}

\author{
${ }^{1}$ Department of Obstetrics and Gynecology, Government Medical College Srinagar, Jammu and Kashmir, India \\ ${ }^{2}$ Aruna Asif Ali Government Hospital, Tis Hazaari, Delhi, India \\ ${ }^{3}$ District Hospital Kishtwar, Jammu and Kashmir, India
}

Received: 03 December 2016

Accepted: 28 December 2016

\section{*Correspondence: \\ Dr. Samar Mukhtar, \\ E-mail: smsamarsiddiqi@gmail.com}

Copyright: $\odot$ the author(s), publisher and licensee Medip Academy. This is an open-access article distributed under the terms of the Creative Commons Attribution Non-Commercial License, which permits unrestricted non-commercial use, distribution, and reproduction in any medium, provided the original work is properly cited.

\section{ABSTRACT}

Background: Abnormal uterine bleeding is one of the leading causes for seeking gynaecological advice. The aim and objectives of the study was to determine the pattern of hysteroscopic abnormalities and histopathological features of Abnormal Uterine Bleeding and to correlate hysteroscopic findings with histopathological findings.

Methods: The present study "Role of Hysteroscopy and Histopathology in Evaluating patients with Abnormal Uterine Bleeding" was an observational study carried out in the Postgraduate Department of Obstetrics and Gynaecology and Postgraduate Department of Pathology of Government Medical college, Srinagar after obtaining clearance from the institutional ethical committee. The period of the study was One and a Half Years from April 2014 to September 2015.

Results: The most common abnormality detected by hysteroscopy was Endometrial Hyperplasia (27 cases, 27\%) followed by endometrial polyps ( 21 cases, $21 \%$ ). Endometrial Hyperplasia was the most common abnormality found in Menorrhagia followed by polyps while polyps were the most common finding in polymenorrhea and endometrial hyperplasia was the most common pathology in postmenopausal bleeding. Hysteroscopy had a sensitivity of $93.2 \%$, specificity of $83.9 \%$, positive predictive value of $82 \%$, Negative Predictive Value of $94 \%$ in diagnosing etiology of abnormal uterine bleeding.

Conclusions: This study confirms that hysteroscopy has a definitive role in evaluating patients with abnormal uterine bleeding and hysteroscopy and histopathology complement each other in the evaluation of a patient with Abnormal uterine bleeding.

Key words: Endometrial hyperplasia, Hysteroscopic abnormalities, Menorrhagia

\section{INTRODUCTION}

Abnormal uterine bleeding is one of the leading causes for seeking gynaecological advice. The incidence of Abnormal Uterine Bleeding is $30-40 \%$ of all gynaecological cases quoted by Devi and Menon. ${ }^{1}$

The international federation of gynaecology and obstetrics (FIGO) has approved a new classification system (polyps, adenomyosis, leiomyoma, malignancy and hyperplasia - coagulopathy, ovulatory disorders, endometrial causes, iatrogenic, not classified [PALMCOEIN]) for causes of Abnormal Uterine Bleeding in non gravid women of reproductive age. ${ }^{2}$

Hysteroscopy has ushered a new era in the evaluation of abnormal uterine bleeding. By direct visualization of uterine cavity it is able to pin point the etiology. ${ }^{3}$

Hysteroscopy allows direct visualization of the endometrial cavity and importantly, directed endometrial sampling of any suspicious areas. ${ }^{4}$ 


\section{Aims and objectives}

1. To determine the pattern of hysteroscopic abnormalities in Abnormal Uterine Bleeding.

2. To determine the Histopathological features of Abnormal Uterine Bleeding.

3. To correlate hysteroscopic findings with histopathological findings.

\section{METHODS}

The present study "Role of Hysteroscopy and Histopathology in Evaluating patients with Abnormal Uterine Bleeding" was an observational study carried out in the Postgraduate Department of Obstetrics and Gynaecology, Government Lalla Ded Hospital of Government Medical college, Srinagar and Postgraduate Department of Pathology of Government Medical college, Srinagar after obtaining clearance from the institutional ethical committee. The period of the study was One and a Half year from April 2014 to September 2015. 100 consecutive cases of abnormal uterine bleeding were taken up for the study. All the patients in this study underwent Hysteroscopy followed by Hysteroscopic guided biopsy or Dilatation and Curettage and the biopsy specimen or curettings were sent for Histopathological analysis.

Both Parous and nulliparous women with age between 25-60 years with Abnormal Uterine Bleeding who did not require any emergency management were included in the study. Patients with severe anaemia due to menorrhagia, with profuse bleeding, with large or multiple fibroids, patients with infection in the uterine tract and pregnant women were excluded from the study.

Patients were selected by diagnosis on History, General Physical Examination, Abdominal and Pelvic Examination and Routine investigations. Patients were informed in local language about the study/ procedure and written consent was obtained. Hysteroscopy was performed under General anesthesia.

The instrument used was a Karl Storz hysteroscope. Patients were placed in the lithotomy position and the position of the uterus confirmed by bimanual examination. The Hysteroscope was connected to the distention medium which was Normal Saline or Glycine. The Hysteroscope was introduced into the cervical canal under direct vision until the whole uterine cavity and fundus were seen to be well distended. Each uterine cornua was identified and the cavity inspected for pathological lesions. Hysteroscopic guided biopsy or polypectomy was performed wherever suspicious area present or a full Dilatation and Curettage was done.

The specimens were sent to the Department of Pathology, Government Medical College for Histopathological examination. Statistical package for social sciences
(SPSS - Version 16.0) was used to carry out the statistical analysis of data.

\section{RESULTS}

In the present study, hysteroscopy was performed in 100 patients presenting with complaints of abnormal uterine bleeding followed by hysteroscopic biopsy or curettage. The specimen was sent for histopathologic examination. The hysteroscopic and histopathologic patterns were studied and the measures of validities were computed taking histopathology as the gold standard.

Table 1: Age distribution of patients.

\begin{tabular}{|lll|}
\hline Age (years) & No. of patients & Percentage \\
\hline $25-30$ & 10 & 10 \\
\hline $31-40$ & 49 & 49 \\
\hline $41-50$ & 33 & 33 \\
\hline $51-60$ & 8 & 8 \\
\hline Total & 100 & 100 \\
\hline
\end{tabular}

Table 2: Clinical presentation of patients.

\begin{tabular}{|lll|}
\hline Presentation & No. of Patients & Percentage \\
\hline Menorrhagia & 53 & 53 \\
\hline Polymenorrhea & 17 & 17 \\
\hline $\begin{array}{l}\text { Post menopausal } \\
\text { bleeding }\end{array}$ & 15 & 15 \\
\hline Polymenorrhagia & 13 & 13 \\
\hline Metrorrhagia & 2 & 2 \\
\hline
\end{tabular}

In the present study, age group included was 25-60 years. Maximum age incidence was between 31-40 years (49\%). Among the 100 patients, majority of the patients (53 cases, 53\%) presented with complaints of menorrhagia, followed by Polymenorrhea (17 cases, 17\%). Postmenopausal bleeding was present in $15 \%$ cases, polymenorrhagia in $13 \%$ cases while metrorrhagia was seen in $2 \%$ cases.

Table 3: Findings at hysteroscopy.

\begin{tabular}{|lll|}
\hline Findings & No. of patients & Percentage \\
\hline Normal & 50 & 50 \\
\hline $\begin{array}{l}\text { Endometrial } \\
\text { hyperplasia }\end{array}$ & 27 & 27 \\
\hline Endometrial polyps & 21 & 21 \\
\hline Submucous myoma & 2 & 2 \\
\hline
\end{tabular}

Table 4: Findings at histopathology.

\begin{tabular}{|lll|}
\hline Findings & No. of patients & Percentage \\
\hline Normal & 56 & 56 \\
\hline $\begin{array}{l}\text { Endometrial } \\
\text { hyperplasia }\end{array}$ & 27 & 27 \\
\hline Endometrial polyps & 16 & 16 \\
\hline Endometritis & 1 & 1 \\
\hline
\end{tabular}


Abnormal findings were diagnosed in 50 cases (50\%), while in the remaining 50 cases, normal endometrium was seen on hysteroscopy. The most common abnormality detected was Endometrial Hyperplasia (27 cases, 27\%) followed by endometrial polyps (21 cases, $21 \%$ ) while Submucous myomas were detected in 2 cases $(2 \%)$.

Table 5: Correlation of type of abnormal uterine bleeding with histopathology.

\begin{tabular}{|c|c|c|c|c|c|}
\hline \multirow[b]{2}{*}{$\begin{array}{l}\text { Clinical } \\
\text { presentation }\end{array}$} & \multicolumn{4}{|c|}{ Findings at histopathology } & \\
\hline & $\begin{array}{l}\overline{\mathscr{T}} \\
\text { है } \\
\text { Z }\end{array}$ & 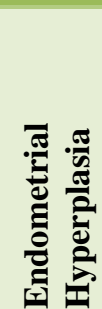 & 20 & & Total \\
\hline Menorrhagia & 31 & $\sqrt{13}$ & 9 & 0 & 53 \\
\hline Polymenorrhea & 13 & 1 & 3 & 0 & 17 \\
\hline $\begin{array}{l}\text { Post menopausal } \\
\text { bleeding }\end{array}$ & 2 & 3 & & 0 & 15 \\
\hline Polymenorrhagia & 8 & 3 & 1 & 1 & 13 \\
\hline Metrorrhagia & 2 & 0 & 0 & 0 & 2 \\
\hline Total & 56 & 27 & 16 & 1 & 100 \\
\hline
\end{tabular}

Table 6: Correlation of type of AUB with hysteroscopy.

\begin{tabular}{|c|c|c|c|c|c|}
\hline \multirow[b]{2}{*}{$\begin{array}{l}\text { Clinical } \\
\text { presentation }\end{array}$} & \multicolumn{4}{|c|}{ Findings at histopathology } & \multirow[b]{2}{*}{ Total } \\
\hline & בే & 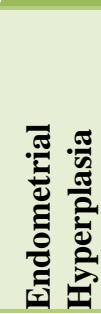 & है & & \\
\hline Menorrhagia & 30 & 12 & 9 & 2 & 53 \\
\hline Polymenorrhea & 11 & 1 & 5 & 0 & 17 \\
\hline $\begin{array}{l}\text { Post menopausal } \\
\text { bleeding }\end{array}$ & 1 & 10 & 4 & 0 & 15 \\
\hline Polymenorrhagia & 7 & 3 & 3 & 0 & 13 \\
\hline Metrorrhagia & 1 & 1 & 0 & 0 & 2 \\
\hline Total & 50 & 27 & 21 & 2 & 100 \\
\hline
\end{tabular}

Of the 53 patients with menorrhagia, 31 cases had normal endometrium on histopathology, 13 cases had endometrial hyperplasia while Endometrial polyps were detected in 9 cases. Among the 17 patients with polymenorrhea, polyps were detected on histopathology in 3 cases and hyperplasia was present in 1 case. Of the 15 patients with postmenopausal bleeding, 10 patients had endometrial hyperplasia on histopathology, 3 patients had polyps while 2 patients had normal endometrium on histopathology. Of the 13 patients with polymenorrhagia, histopathology detected normal endometrium in 8 patients, 3 patients had hyperplasia and there was one case each of polyp and endometritis. Both the cases of metrorrhagia had normal endometrium.

\section{Table 7: Hysteroscopic and histopathological correlation in study patients.}

\begin{tabular}{|c|c|c|c|c|c|}
\hline \multirow[b]{2}{*}{$\begin{array}{l}\text { Hysteroscopy } \\
\text { findings }\end{array}$} & \multicolumn{4}{|c|}{$\begin{array}{l}\text { Findings at } \\
\text { histopathology }\end{array}$} & \multirow[b]{2}{*}{ Tota } \\
\hline & हี & 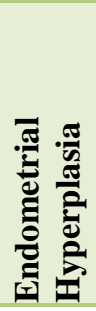 & ᄅ̃ & 을 & \\
\hline Normal & 47 & 2 & 0 & 1 & 50 \\
\hline $\begin{array}{l}\text { Endometrial } \\
\text { hyperplasia }\end{array}$ & 2 & 25 & 0 & 0 & 27 \\
\hline Endometrial polyps & 5 & 0 & 16 & 0 & 21 \\
\hline Submucous myoma & 2 & 0 & 0 & 0 & 2 \\
\hline Total & 56 & 27 & 16 & 1 & 100 \\
\hline
\end{tabular}

Among the 53 patients with menorrhagia, endometrial hyperplasia was seen in 12 patients, endometrial polyps in 9 patients and submucus myomas in 2 patients. Of The 17 patients with polymenorrhea, 5 patients had endometrial polyps and one patient had endometrial hyperplasia. Of the 15 patients with postmenopausal bleeding, 10 patients had endometrial hyperplasia, 4 patients had endometrial polyps and one patient had normal endometrium on hysteroscopy. Of the 13 patients with polymenorrhagia, 3 patients had endometrial hyperplasia and 3 patients had endometrial polyps. Out of the 2 patients of metrorrhagia, 1 case had normal endometrium and 1 case had hyperplastic endometrium detected on hysteroscopy.

Of the 50 cases showing normal endometrium on hysteroscopy, 47 patients had normal endometrium on histopathology as well, 2 cases had hyperplasia and one case had endometritis detected on histopathology. Of the 27 cases showing hyperplasia on hysteroscopy, 25 had hyperplasia on histopatholgy as well while 2 patients had normal endometrium on histopathology examination.

Of the 21 cases showing endometrial polyps on hysteroscopy, histopathology detected polyps in 16 cases and 5 cases were described as normal. 2 cases of submucous myomas were detected on hysteroscopy. In this study, hysteroscopy had a sensitivity of $93.2 \%$, specificity of $83.9 \%$, positive predictive value of $82 \%$, Negative Predictive Value of $94 \%$ in diagnosing etiology of abnormal uterine bleeding. For detecting hyperplasia, hysteroscopy has a sensitivity of $92.6 \%$, specificity of $97.3 \%$, Positive Predictive Value of $92.6 \%$, Negative Predictive Value of $97.3 \%$. For detecting endometrial polyps, hysteroscopy has a sensitivity of $100 \%$, specificity of $94.1 \%$, Positive Predictive Value of $76.2 \%$, Negative Predictive Value of $100 \%$. 


\section{DISCUSSION}

Abnormal uterine bleeding is one of the leading causes of seeking gynecological advice. The causes of Abnormal Uterine Bleeding and its differential diagnosis are heterogeneous and complex .Hysteroscopy has ushered a new era in the evaluation of abnormal uterine bleeding. By direct visualization of uterine cavity it is able to pin point the etiology. ${ }^{3}$ Hysteroscopy should ideally be done in all cases where a transvaginal ultrasound reveals a thickened endometrium. ${ }^{5}$ Diagnostic hysteroscopy is a commonly performed gynecologic procedure to evaluate the endometrial cavity. Broadly, 2 systems of diagnostic hysteroscopy exist: Panoramic and Contact.

The age group studied was 25-60 years .The maximum incidence found was between 31-40 years (49\%) with the youngest patient being 26 years and oldest patient 60 years old; these findings are being supported by Sangeeta Series $^{6}$ in which maximum age incidence was between $31-40$ years $(56 \%)$ and Dirgha ${ }^{7}$ series in which maximum age incidence was between $31-40$ years $(42.7 \%)$. The commonest presenting complaint in this series was menorrhagia $(53 \%)$ followed by polymenorrhea $(17 \%)$ followed by Postmenopausal bleeding (15\%). These findings are supported by Phalak $\mathrm{R}^{8}$ series in which $60 \%$ of the cases had menorrhagia and Aisha Razzaq ${ }^{9}$ series in which menorrhagia was seen in $38.8 \%$ cases.

Of the 50 cases with abnormal findings on hysteroscopy, commonest pathology seen was Endometrial hyperplasia $(27 \%)$ followed by endometrial polyps $(21 \%)$ and submucous myomas were seen in $2 \%$ of the cases; these findings are being supported by Phalak $\mathrm{R}^{8}$ series in which hyperplasia was found in $40 \%$ cases, Polyps were found in $32 \%$ cases and submucous fibroids were seen in $8 \%$ cases. In this study, histopathology showed abnormal findings in 44 cases (44\%). Of these, 27 cases had hyperplasia, 16 cases had polyps and 1 case had endometritis; these findings are in accordance with Phalak Rajesh ${ }^{8}$ in which abnormal histopathology findings were present in $44 \%$ cases of which $45.46 \%$ cases had hyperplasia, $27.27 \%$ cases had polyps and 9.09\% cases had submucosal fibroids and Aisha Razzaq ${ }^{9}$ series in which histopathology detected abnormalities in $60 \%$ cases of which hyperplasia was present in $20 \%$ cases, polyps in $18.8 \%$ cases and fibroids in $11.3 \%$ cases.

Of the 50 cases showing normal endometrium on hysteroscopy, 47 patients had normal endometrium on histopathology as well, 2 cases had hyperplasia and one case had endometritis detected on histopathology. Statistically, true positives were 41 , false positives 9 , true negatives 47 and false negatives were 3 . Calculating these data, hysteroscopy had a sensitivity of $93.2 \%$, specificity of $83.9 \%$, positive predictive value of $82 \%$, negative predictive value of $94 \%$ and diagnostic accuracy of $88 \%$ for diagnosing etiology of abnormal uterine bleeding; These results are being supported by Phalak $\mathrm{R}^{8}$ series which showed hysteroscopy to have a sensitivity of
$95.65 \%$, specificity of $88.46 \%$, positive predictive value of $88 \%$, negative predictive value of $95 \%$ and diagnostic accuracy of $91.84 \%$ and Pop Trajković Dinić $\mathrm{S}^{10}$ series in which hysteroscopy had a sensitivity of $100 \%$ in the detection of intrauterine pathology, specificity of $81 \%$, the positive predictive value of $92 \%$ and the negative predictive value of $100 \%$.

Of the 27 cases showing hyperplasia on hysteroscopy, 25 had hyperplasia on histopatholgy as well while 2 patients had normal endometrium on histopathology examination. Hence, true positives were 25 , false positives 2 , false negatives 2 and true negatives 71 , hence hysteroscopy had a sensitivity of $92.6 \%$, specificity of $97.3 \%$, positive predictive value of $92.6 \%$, negative predictive value of $97.3 \%$ and accuracy of $96 \%$; these findings are being supported by Torrejon $\mathrm{R}^{11}$ series in which sensitivity was $71.8 \%$ and specificity $96.4 \%$.

Of the 21 cases showing endometrial polyps on hysteroscopy, histopathology detected 16 cases and 5 cases were described as normal. Thereby, true positives were 16 , false positives 5 , false negative 0 and true negatives 79. Hence hysteroscopy had a sensitivity of $100 \%$, specificity of $94.1 \%$, positive predictive value of $88 \%$, negative predictive value of $100 \%$ and accuracy of $96 \%$. These findings are being supported by Tajossadat ${ }^{12}$ series in which hysteroscopy had a sensitivity of $93 \%$, specificity of $100 \%$, positive predictive value of $100 \%$, negative predictive value of $95.4 \%$ in diagnosing endometrial polyps.

Measures of validities for submucous myomas were not calculated as only 2 cases of submucous myomas were detected.

\section{CONCLUSION}

This study confirms that hysteroscopy has a definitive role in evaluating patients with abnormal uterine bleeding. Hysteroscopy is a safe and reliable procedure in the diagnosis of cases with abnormal uterine bleeding with high sensitivity, specificity, positive predictive value and negative predictive value. The results of hysteroscopy are immediately available. Hysteroscopy and histopathology complement each other in the evaluation of a patient with abnormal uterine bleeding for accurate diagnosis and further treatment of abnormal uterine bleeding.

\section{Funding: PSG Hospital \\ Conflict of interest: None declared \\ Ethical approval: The study was approved by the Institutional Ethics Committee}

\section{REFERENCES}

1. Menon MKK, Devi PK, Rao KB. Postgraduate Obstetrics and Gynecology, India: Orient Longman; 1982: pg 253. 
2. Sharma JB, Yadav M. New ground breaking International Federation of Gynecology and Obstetrics's classification of abnormal uterine bleeding: Optimizing management of patients. J Midlife Health. 2013;4(1):42-5.

3. Sunitha C, Somalatha R. Clinical study of diagnostic hysteroscopy in abnormal uterine bleeding and its histopathological correlation. IOSR Journal of Dental and Medical Sciences. 2013;5(3):43-6.

4. Shruti M, Page LM. Diagnosis of abnormal uterine bleeding. Best Practice and Research Clinical Obstetrics and Gynaecology. 2007;21(6):891-903.

5. Jeffcoate's Principles of Gynaecology. Eighth Edition; Narendra Malhotra, Pratap Kumar; Abnormal and Excessive Uterine Bleeding; page 569. 1998.

6. Mukhopadhyay SR, Ashis K. Correlation between Diagnostic Hysteroscopy And Its Histopathological Examination In The Evaluation Of Abnormal Uterine Bleeding. Indian J Prev Soc Med. 2014;45(1-2).

7. Pamnani A, Modi K. Hysteroscopy: An Additional Tool to D and C for Evaluation of Abnormal Uterine Bleeding, Research paper Obstretrics and Gynaecology. 2014;4(11).
8. Phalak R, Rawal R, Mule VD. Hysteroscopy as a Diagnostic Aid in Gynecology; International Journal of Interdisciplinary and Multidisciplinary Studies. 2015;2(10):78-83.

9. Aisha R, Shukar-ud-Din S. Role of diagnostic hysteroscopy in case of abnormal uterine bleeding Pak J Surg. 2011;27(4):309-15.

10. Pop Trajković Dinić S, Ljubić A, Kopitović V. The role of hysteroscopy in diagnosis and treatment of postmenopausal bleeding. Vojnosanit Pregl. 2013;70(8):747-50.

11. Torrejon R, Fernandez-Alba JJ, Carnicer I, Martin A. The value of hysteroscopic exploration for abnormal uterine bleeding. J Am Assoc Gynecol Laparosc. 1997;4(4):453-6.

12. Tajossadat A, Fereshteh M. Diagnostic value of hysteroscopy in abnormal uterine bleeding compared to pathology reports. Iranian Journal of Reproductive Medicine. 2007;5(2):61-4.

Cite this article as: Firdous N, Mukhtar S, Bilal S, Beigh SK. Role of hysteroscopy and histopathology in evaluating patients with abnormal uterine bleeding. Int J Reprod Contracept Obstet Gynecol 2017;6:615-9. 